Fixed Point Theory, 20(2019), No. 2, 407-416

DOI: $10.24193 /$ fpt-ro.2019.2.26

http://www.math.ubbcluj.ro/ nodeacj/sfptcj.html

\title{
ON THE EXTENDED MULTIVALUED SUZUKI TYPE CONTRACTIONS VIA A TOPOLOGICAL PROPERTY
}

\author{
HOJJAT AFSHARI* AND HASSEN AYDI** \\ * Department of Mathematics, Basic Science Faculty, University of Bonab \\ Bonab, Iran \\ E-mail: hojat.afshari@yahoo.com \\ ** Université de Sousse, Institut Supérieur d'Informatique et des Techniques de Communication \\ H. Sousse 4000, Tunisia \\ Department of Medical Research, China Medical University Hospital \\ China Medical University, Taichung, Taiwan \\ E-mail: hassen.aydi@isima.rnu.tn
}

Abstract. In this paper, by using the idea of Suzuki, we present some new results on absolute retractivity of the common fixed points set of multivalued Suzuki type contractions.

Key Words and Phrases: Absolute retract, fixed point, Suzuki contractive multifunction. 2010 Mathematics Subject Classification: 47H10, 54H25.

\section{REFERENCES}

[1] H. Afshari, Topological properties of tripled fixed points set of multifunctions, Matemat. Vesnik, 68(2016), no. 4, 277-286.

[2] H. Afshari, H.H. Alsulami, E. Karapinar, On the extended multivalued Geraghty type contractions, J. Nonlinear Science Appl., 9(2016), 4695-4706.

[3] H. Afshari, S. Kalantari, H. Aydi, Fixed point results for generalized $\alpha-\psi$-Suzuki-contractions in quasi-b-metric-like spaces, Asian-European J. Mathematics, 11(2018), no. 1, 1850012 (12 pages).

[4] H. Afshari, Sh. Rezapour, N. Shahzad, Absolute retractivity of the common fixed points set of two multifunctions, Topological Meth. in Nonlinear Anal., 40(2012), 429-436.

[5] H. Afshari, Sh. Rezapour, N. Shahzad, Some results on absolute retractivity of the fixed points set of KS-multifunctions, Math. Slovaca., 65(2015), no. 6, 1509-1516.

[6] S.M.A. Aleomraninejad, Sh. Rezapour, N. Shahzad, On fixed point generalizations of Suzuki's method, Appl. Math. Lett., 24(2011), 1037-1040.

[7] M.C. Alicu, O. Mark, Some properties of the fixed points set for multifunctions, Stud. Univ. Babeş-Bolyai Math., 25(1980), no. 4, 77-79.

[8] H. Aydi, M. Abbas, C. Vetro, Partial Hausdorff metric and Nadler's fixed point theorem on partial metric spaces, Topology and its Appl., 159(2012), 3234-3242.

[9] H. Aydi, A. Felhi, S. Sahmim, A Suzuki fixed point theorem for generalized multivalued mappings on metric-like spaces, Glasnik Mathem., 52(72)(2017), 147-161.

[10] R.K. Bose, Some Suzuki type fixed point theorems for multi-valued mappings and applications, International J. Pure and Applied Math., 92(2014), no. 4, 481-497. 
[11] M. Kikkawa, T. Suzuki, Three fixed point theorems for generalized contractions with constants in complete metric spaces, Nonlinear Anal., 69(2008), 2942-2949.

[12] M. Kikkawa, T. Suzuki, Some similarity between contractions and Kannan mappings, Fixed Point Theory Appl., (2008), Art. ID 649749, 8 pages.

[13] H. Schirmer, Properties of the fixed point set of contractive multifunctions, Canadian Math. Bull., 13(1970), no. 2, 169-173.

[14] A. Sintamarian, A topological property of the common fixed points set of two multivalued operators, Nonlinear Anal., 70(2009), 452-456.

[15] A. Sintamarian, A topological property of the common fixed points set of two multivalued operators satisfying a Latif-Beg type condition, Fixed Point Theory, 9(2008), no. 2, 561-573.

[16] T. Suzuki, A generalized Banach contraction principle that characterizes metric completeness, Proc. Amer. Math. Soc., 136(2008), 1861-1869.

[17] T. Suzuki, Fixed point theorems and convergence theorems for some generalized nonexpansive mappings, J. Math. Anal. Appl., 340(2008), 1088-1095.

Received: June 27, 2017; Accepted: May 10, 2018. 